\title{
The Design of Interactive Teaching Model for College English Course in Web-based teaching model
}

\author{
Zeng-Ying \\ Wuchang Institute of Technology, \\ Wuchang, Wuhan, Hubei 430065 China nxzengying@163.com
}

\begin{abstract}
Traditional college English teaching model centered on grammar and words teaching. However, information technology brings about a reformation in college English teaching model. According to constructivism, language teaching requires plenty of raw materials and practice in real life. Web could serve as a tool for language learners to collect raw materials and a channel to communicate efficiently. Combined with web resources and technology, in the model of web-based interactive teaching model, teachers and students could interact with each other through various access, which will not only stimulate students' learning interest, but also raise learning efficiency.
\end{abstract}

Key words- teaching model; interactive; college English; web-based

\section{INTRODUCTION}

The third batch of undergraduate educational institutes differ from those of the first and the second in many ways. As far as students' English level and learning features are concerned, students from the third batch seem to be more dependent on teachers' guidance; in other words, they are less self-disciplined in their study. Meanwhile, web-based teaching model spreads rapidly in educational system nowadays, and this teaching model requires students to be highly self-disciplined during their study process. Hence it is necessary to make further research on how to design a proper teaching model in order to solve this problem.

\section{Research background}

In 2004, Ministry of Education of People's Republic of China has promulgated an announcement for college English education, in which multiple teaching model has been in requirement. Since then, universities and colleges have been actively joining in the exploration of new teaching model for college English education. Multimedia-assisted classroom and web-based autonomous learning center have been set up in many educational institutes. These new information technology and teaching platform enable teachers to adopt various teaching methodology and take a hack at different teaching models, among which the interactive teaching model is greatly favored. However, attributed to some factors such as teachers' lack of extra hours and energy, or their lack of necessary training in computer skills, web-based interactive teaching model for college English education remains rare, or works with very low efficiency. Hence we propose to conduct a research on how to design a suitable web-based interactive teaching model for college English course. As students in different levels of educational institutes are of different English competence and of different learning features, it 
is necessary to make it clear that the object of this research is referred only to the students in the third batch of undergraduate educational institutes.

Compared with their counterparts in higher-level universities and colleges, students of the third batch keep with their own features. They are comparatively weak in English competence and more active in operating. Besides, students in educational institute of the third batch are supposed to be trained as graduates with application abilities.

\section{Theories about interactive teaching model}

Interactive teaching model is implemented with the theoretic support of constructivism as its main theory basis. According to the constructivists, students are the subject of cognitive activities instead of being a subject receiving information and knowledge passively. Learning activities occurs in an interactive environment among teachers, students, media and learning resources. Constructivism believes that it is highly important for teachers to generate students' autonomous learning ability. Meanwhile, teacher, instead of being the center, should shift his role as a guider, organizer and assistant.

In 1982, Palincsar initiated interactive teaching model, which follows the guidance of constructive theory in teaching methodology. This teaching model emphasizes that students should be the center of all teaching activities. Whereas, teachers should present with meaningful raw language materials and set up practical language atmosphere to promote students in language learning. During the teaching procedure, teachers actively encourage students to take part in the teaching activities, divide students into several groups, so that students would be able to interact with their classmates. By so doing, students may get actively involved in the teaching procedure, and learn language creatively. Since language is a tool for communication, interactive teaching model suits well for the teaching aim by inviting and absorbing students into the teaching activities.

It is obvious that in the traditional interactive teaching model, interaction occurs between teacher and students. The benefit of traditional interactive teaching model lies in that teacher knows his students well for they interact with each other in a higher level of frequency. Whereas, this model lacks of sufficient raw material of the real life. Besides, due to the limitation of area and time, opportunities of putting linguistic knowledge learned in traditional class into practical usage are very few. These shortcomings of traditional interactive teaching model undermines students' interest in and motivation to participate actively in teaching activities.

According to the U.S. psychologist Bandura(1977), the process of learning involves vicarious process, cognitive process and self-regulatory process. This theory believes that action, cognition and environment are of great influence in learning process, and that learner himself should participate actively in learning activities instead of being pushed to learn. Thus, for a teacher as the designer of students' learning process, the question of how to generate students' interest and encourage them to learn actively becomes an important issue waiting for discussion.

With the development of information technology and the popularization of internet, web-based teaching model may as well offer a solution to the shortcomings of traditional interactive teaching model, for internet produces a mass of raw materials for language learning 
and generates various chances for students to practice their linguistic competence, for example, writing emails and chatting in English, selecting information needed for class, etc..

\section{Specific description of web-based interactive teaching model}

Web-based interactive teaching model differs from traditional interactive teaching model in that this model covers three bodies instead of two in the interaction, i.e., teachers, students and the web. Hence, it is necessary to discuss how to manage relationship among these three bodies.

In concern with the third batch institute students' English level and their study habits, we believe that students' on-line learning should be an action under teachers' guidance and supervision instead of pure autonomous action. In this case, three sorts of relation should be taken into consideration, i.e. the relation between teacher and students, relation between students and web platform and relation between teacher and the web. All these three sorts of relation are centered on the main subject, namely, the students. And the three bodies serve for a single goal, that is, to improve students' efficiency and effectiveness of learning English.

\subsection{Teacher and students}

Internet offers a mass of raw materials for English learning. As most

students from the third batch lack necessary knowledge of cognitive strategy and metacognitive strategy about language learning, as well as that they are less self-disciplined in general than their counterpart in higher-level universities and colleges, it is very likely for them to lose their control and slip into doing things unrelated to English learning when they surf on the internet. Hence it is highly important for teachers to gather information about their students on their individual linguistic competence and study tendency. Based on this information, teachers should offer corresponding guidance to students on their English learning and assign on-line task accordingly.

As for the guidance, teachers should first give lessons about cognitive strategy and metacognitive strategy about web-based teaching model to ensure that students understand what they are required to do in different teaching process. For example, in the process of class study, students are required to make preparation before taking a class by checking information on the internet, and are required to present his fruits in the class; in the process of web-based study, students are required to do assignments given in the class. All through these process, students should be well aware of what they are doing, why they are doing that and what they are supposed to harvest by so doing. It is noticed that when learners keep in awareness of their own actions, motivations of learning actively will be strengthened and the learning efficiency will be raised.

Followed by the guidance, what teachers should do next is to assign study tasks for students to fulfill through webs. Tasks should be completed either by individuals by in groups, depending on the teaching goals. One principle should be emphasized that in the process of doing these tasks, interaction should be involved as much and frequently as possible. The interaction could be that between students and teachers and among students themselves as well. Different from traditional interaction, under the teaching model based on webs, interaction could also be implemented through internet. And this access of interaction is greatly recommended in 
this teaching model. In fact, this is the very value of web-based teaching model for college English education. Since linguistic competence is supposed to be trained in an interactive way, and web offers various channels to make people communicate with better convenience, and language is this tool for people to communicate, web-based interactive teaching model perfectly joints them together and language learning efficiency is within reach.

\subsection{Students and web}

As mentioned above, students in the third batch are of less self-discipline with more interest in application, grammar-and-words-oriented teaching model is not in their favor. In the new teaching model, teachers assign web tasks properly both in amount and difficulty, so that students may well finish their tasks accordingly. When students are doing assignments, they have clear purpose of what to do, apply their knowledge and strengthen their abilities to solve problems.

Nevertheless, to do web tasks should not be that of a free process. Teachers should keep students in supervision on their schedule in case that students may lose self-control and fall into entertainment in the process of doing tasks. To further stimulate students' interest in participating, formative testing should be arranged in the web tasks. Students should do the test to check up their study effect and make adjustment in learning strategy. Meanwhile, teachers should check up students' performance in the test and give guidance on how to adjust learning strategy.

Except for the assignment, students will have free hours provided by school to surf on the internet in school's autonomous learning center, covering learning resources and software in several categories to learn autonomously. Suggested learning materials are divided into the following sorts: listening and speaking system, ESP learning materials, teacher-consulting system, video lectures, examination exercises, oral learning materials, and culture resources, etc.. By categorizing, students can select materials to their needs and learn with efficiency.

Traditionally, college English class is distributed with four periods, i.e. two classes per week. Classes are given in traditional classrooms. In web-based interactive teaching model, part of the four periods will be conducted in the autonomous learning center, where students could surf on the internet to do tasks assigned by teachers. The amount of learning hours in the center depends on students' learning capability and their langue level. For students of lower level, one period would be suggested; for students of higher level, two or three periods would be suggested. This is because the higher the students' level is, the more self-disciplined the students will be.

In addition to the above suggestion, the amount of learning periods in the learning center could also be distributed from one to two periods as students' level grows. Normally students have to take college English class in the first four semesters, and their language level is supposed to grow after each semester. Therefore, in the first semester, as students' level are comparatively low, all the four periods of class per week should be given in traditional class; in the second semester, one period per week could be given in the learning center, and the rest can be done in a sequence. Thus in the fourth semester, if students' level is competent, all the four periods could be given in the learning center.

One thing should be noticed is that except for the traditional classes, schools offer extra amount of free hours for students to learn 
autonomously in the learning center. For example, schools offer thirty free hours for students to learn autonomously in the learning center in addition to their normal class(four periods per week), besides, another ten free hours will also be given to students in case they need more time to finish their tasks.

In the whole process of study in the learning center, students are not without guidance to ensure that students are performing in the right way.

\subsection{Teachers and webs}

It should be admitted that some of the teachers are not quite capable of operating computers well. Though computers offer a mass coverage of language learning resources, without proficient computer operating skills, it influence is limited. So in the web-based interactive teaching model, teachers are required to take professional computer operating skills.

In addition, teachers should play the role as information provider. Resources of language learning in the learning center should be refreshed regularly, so that students could always find something new to learn. Hence teachers should keep in touch with the latest learning information and make collection.

Besides, teachers should check students' performance in the tests in time, help students to assess their learning effect, analyze their performance and give proper guidance for students to adjust their learning strategy in the next procedure.

The web-based interactive teaching model involves the interaction among teacher, students and webs. Teacher serves as the guidance and information provider, students are the center of the whole teaching procedure, and web(learning center) severs as a tool for teachers and students to communicate. Through frequent communication, students could apply language knowledge into practical usage in the real life environment. Except for that, plenty of raw language materials are available, which enables students to choose learning materials according to their tendency. Thus, students would participate in the learning activities actively and efficiently.

\section{Conclusion}

As more language learning centers set up, web-based interactive teaching model will be applicable in a wider field. Students in different batches of educational institutes have different linguistic competence and of different learning tendency, hence it is necessary to design teaching models accordingly to meet with different educational requirements from students. Web-based interactive teaching model based on the theory of constructivism and social psychology, absorbing the fruit of the development of information technology, aims to improve the traditional interactive teaching model and to better serve education of college English in the third batch of graduate institutes. As a new teaching model, details of this model design await for further discussion, and experiments need to be conducted so as to check its effectiveness.

\section{Acknowledgement}

This paper is basised on the Hubei provinc, teaching research project. Named "A Resea rch on Design of Interactive Autonomic Lea rning Model for College English Course in Web-based Span", supported by Educationa 1 Commission of Hubei Province 2014. The China

Code of project is 2014420 


\section{Reference}

[1] Bandura, A. Social Learning Theory[M]. Englewood Cliffs, NJ: Prentice Hall, 1977.

[2] E. LI and YING ZENG, A Research on Effects of Web-based Autonomous Learning on Cultivation of Computer Majors' English Competence[J]. $2^{\text {nd }}$ International Conference on Information and Communication Technology for Education, 2015:228-233. 